\title{
La responsabilidady la ética de la Universidad en el entorno social
}

José Roberto Ramírez Gálvez

Departamento de Ciencias Económicas UNAN-MANAGUA, FAREM-Chontales

ramirezgalvezjoseroberto@yahoo.com

DOI: http://dx.doi.org/10.5377/torreon.v6i16.6553

Palabras clave: Universidad, responsabilidad social empresarial, responsabilidad social corporativa, ética empresarial, cultura, mundo globalizado.

\section{RESUMEN}

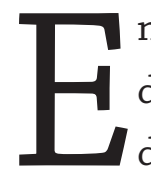

$\mathrm{n}$ el presente artículo se hace referencia al rol que la responsabilidad y la ética de la universidad en el entorno social -considerando los cambios permanentes del mundo globalizado, de las incertidumbres por los cambios permanentes en el campo educativo- juega hoy con sometimiento a mayores exigencias en relación con la calidad de la educación, tanto a nivel local como nacional e internacional, producto de los cambios y de los retos en aras de brindar educación con calidad y con responsabilidad y ética empresarial. La universidad debe interactuar en diálogos con los distintos actores de estudiantes, docentes, empresas y representantes de la sociedad con el fin de obtener mayores criterios de entendimiento acerca de su desempeño y de su responsabilidad social con ética empresarial, identificando los aportes esenciales al desarrollo humano sostenible, pero considerando la responsabilidad y la ética empresarial como sinónimos de alta calidad en la enseñanza universitaria. La universidad debe centrarse en la suma de esfuerzos de todos los actores sociales, que conlleven a la colectividad con gestión de organización socialmente responsable, con formación académica, con producción del saber y con participación del desarrollo humano sostenible, procurando el involucramiento de los actores sociales, relación que incluye clientes, proveedores, socios, consumidores, medio ambiente, comunidades, el gobierno y la sociedad en general, y la consideración de factores sociales, económicos, éticos y responsabilidad social. 
La responsabilidad social empresarial es el: "Hacer negocios basados en principios éticos y apegados a la ley". La empresa (no el empresario) tiene un rol ante la sociedad, ante el entorno en el cual opera (Bank Group, 2016).

\section{INTRODUCCIÓN}

La responsabilidad social empresarial (RSE), no es una cultura de la filantropía, no se busca que las empresas se conviertan en obras de beneficencia, ya que las empresas están hechas para ser rentables. Esto implica que las empresas adopten una postura activa y responsable en torno al impacto de sus operaciones. Esta cultura es una forma de hacer negocios que le garantiza mayor sostenibilidad a lo largo del tiempo a la empresa y crecimiento económico.

La responsabilidad social empresarial (RSE), es el rol que le toca jugar a las empresas a favor del desarrollo sostenible, es decir, a favor del equilibrio entre el crecimiento económico, el bienestar social y el aprovechamiento de los recursos naturales y el medio ambiente. Este equilibrio es vital para la operación de los negocios. Las empresas deben pasar a formar parte activa de la solución de los retos que tenemos como sociedad, por su propio interés de tener un entorno más estable y próspero.

Las empresas tienen la responsabilidad de conocer el entorno en el que operan. Deben tener un claro conocimiento de todo lo que rodea su empresa, no solo en términos geográficos, sino en términos del conjunto de reglas, leyes que rigen su operación y todas las actividades relacionadas directa e indirectamente con la empresa.

El concepto de Responsabilidad Social Empresarial o Responsabilidad Social Corporativa (RSE o RSC respectivamente), surge en Estados Unidos a finales de los años 50 y principios de los 60. Contrario a lo que se piensa comúnmente, la responsabilidad social empresarial va más allá de prácticas puntuales, iniciativas ocasionales o motivadas por el marketing, las relaciones públicas u otros beneficios empresariales. La RSE es una filosofía corporativa adoptada por la alta dirección de una empresa para actuar en beneficio de sus propios trabajadores, sus familias y el entorno social en las zonas de su influencia. Se la considera como un conjunto integral de políticas, prácticas y programas que se instrumentan en toda la gama de operaciones corporativas y en los procesos de toma de decisiones, y que significa poner en marcha un sistema de administración con procedimientos, controles y documentos (Centro Virtual de Noticias, 2006).

Es importante reconocer que, existen públicos o actores con los que toda empresa se interrelaciona. A estos, se les llama "públicos interesados". Los públicos interesados son todas aquellas personas a quienes el negocio afecta y se ven impactados por la empresa de manera negativa o positiva (Bank Group, 2016). 
La Responsabilidad Social Empresarial se define como los comportamientos de negocio basados en valores éticos y principios de transparencia que incluyen una estrategia de mejoramiento continuo en la relación entre la empresa y sus partes, relación que incluye clientes, proveedores, socios, consumidores, medio ambiente, comunidades, el gobierno y la sociedad en general. "Corresponde a una estrategia de negocios enfocada a incrementar la rentabilidad, competitividad y la sostenibilidad, sirviendo como parte de un nuevo modelo de desarrollo sostenible. El concepto de RSE puede incorporar derechos humanos, medidas de anticorrupción, el medio ambiente, condiciones laborales y actividades dentro de comunidades por medio de alianzas con organizaciones de la sociedad civil”.

Muchas empresas del mundo reconocen hoy los beneficios de incorporar prácticas y políticas socialmente responsables. Igualmente, existen estudios empíricos que demuestran los impactos positivos de la RSE en aspectos como el desempeño financiero, los costos operativos, la imagen de marca y la reputación de las empresas. Sin embargo, la incorporación de políticas y prácticas de RSE en Latinoamérica, es aún incipiente y la mayor parte del interés se presenta en las grandes empresas. No obstante, existe una creciente presión sobre las empresas de la región para que incorporen los conceptos de RSE, no solo con el fin de competir eficientemente, sino incluso, de garantizar acceso a los mercados internacionales, donde gobiernos y consumidores exigen cada vez más este tipo de prácticas (Centro Virtual de Noticias, 2006).

Hay una sutil diferencia en el significado de la Responsabilidad Social Corporativa y de la Responsabilidad Social Empresarial, en la medida en que se distingue entre la empresa y la corporación, entendiendo que esta última incorpora a todas las organizaciones, empresariales o no, independientemente de su tamaño, aunque para muchos, ambas expresiones significan lo mismo.

Sí es unánimemente reconocida la diferencia entre RSE o RSC y responsabilidad Social (RS). La Responsabilidad Social se entiende como el compromiso que tienen todos los ciudadanos, las instituciones - públicas o privadas-y las organizaciones sociales, en general, para contribuir al aumento del bienestar de la sociedad local o global. Es necesario decir que frecuentemente se abrevian indistintamente las tres para referirse a la Responsabilidad Social Corporativa. En todo caso, la responsabilidad social (RS) se aplica no solo a las compañías privadas. La responsabilidad Social Corporativa (RSC), se ha ampliado para incorporar a las agencias gubernamentales y a otras organizaciones que tengan un claro interés en mostrar cómo realizan su trabajo (Wikipedia, 2017).

Las empresas existen para generar dinero, pero más que eso, viven para generar oportunidades de relación, de nuevos nichos de mercado, el dinero es un elemento importante y esencial pero no es el único; hay que analizar el impacto que la empresa produce en el aire, en 
la tierra, en el agua, además de que esto sea un ejercicio de responsabilidad social ahora es una herramienta de competitividad. No podemos olvidar que la sociedad es imparable y demanda un buen producto, con mejor calidad, atención al cliente y que la manera para no quedarse fuera del mercado es entendiendo que el argumento de responsabilidad social es reputación y estrategia para la consolidación de nuestra empresa, con mejor reputación venderemos más, tendremos mejor colaboración de empleados y por tanto, mejores resultados de acuerdo a nuestra estrategia (Duarte, 2012).

Por su parte, Ferrer (2001) señala que, la naturaleza voluntaria en la adopción de la responsabilidad social empresarial es motorizada por la "ética aplicada" entendida como: "La ética empresarial es una parte de la ética aplicada, como lo es toda ética de las organizaciones y de las profesiones, la cual tiene como objeto, reflexionar como aplicar principios a la actividad empresarial" (p. 46). Esto, se traduce no solo en la aplicación de esos principios, sino en la identificación de los beneficios que cada una de esas aplicaciones debe proporcionar a la sociedad (impacto social), qué objetivos o finalidad debe perseguir, y qué valores y hábitos es imprescindible incorporar para alcanzarlas y sostenerlas en el tiempo (Castañeda, Ruiz, Viloria, Castañeda, \& Quevedo, 2007)

\section{La ética de la Universidad en el entorno social}

La ética puede definirse como aquella rama del conocimiento que se encarga de estudiar las acciones morales de la sociedad y sus componentes, así como las normas y reglas que marcan su comportamiento.

La ética es un área de la filosofía que muestra cómo se rigen las bases de la moral vinculando siempre la realización del bien con la felicidad y la realización del mal con la infelicidad y el sufrimiento. La ética es una disciplina teórica que versa sobre lo práctico: la acción, es decir, los hechos. Esta orientación teórica es un marco de reflexión ideal para que todo ser humano tome decisiones de acuerdo al criterio de aquello que es correcto o aquello que es justo.

Durante mucho tiempo, la universidad fue vista como síntesis del saber conocido, encargada de transmitir conocimientos, a partir de sus propios intereses y un tanto aislada de la sociedad, participando indirectamente en la formación de profesionales; en épocas más recientes y dada la existencia de mercados más competitivos y el auge de las tecnologías de la información y la comunicación, en lo que se ha denominado Era de la Información y un poco más hacia la sociedad del conocimiento (Toffler, 1981; Castells, 1997; Drucker, 1998), han generado un cambio en el modo de producción del saber, que han ido modificando el papel de la universidad en la sociedad, generándose un nuevo modo de producción del conocimiento que emerge de necesidades prácticas y demandas del mercado mediante la investigación. 
En la época moderna, se incorpora la investigación como actividad fundamental de la universidad. El hecho de insertar la investigación como función de la universidad permitió a mediados del siglo XIX, una continuidad entre los institutos de investigación y la actividad industrial, mediante la transferencia de los resultados de la investigación.

Los cambios sociales, económicos y políticos producidos en el mundo a mediados del siglo XX, hizo necesaria una adaptación y reestructuración de los pilares que sustentaban y daban sentido a la universidad. Su función como servicio público debe satisfacer las demandas de la sociedad y, por tanto, anticiparse al futuro para preparar a personas capaces de sobrevivir en un tipo de sociedad que cambia a una velocidad abismal y que separa la sociedad en la cual se adquirieron los aprendizajes con la sociedad en la cual se requiere ponerlos en práctica.

El quehacer universitario ha estado centrado en el aprender a conocer y hacer, descuidándose los otros dos pilares fundamentales que rigen la educación de este siglo y que constituyen la base del cooperativismo, expresado de otro modo: el aprender a ser y convivir. En consecuencia, se debe formar y formarse en y para la responsabilidad social, es allí donde la Educación Superior juega un rol protagónico: "una educación orientada por el amor hacia la humanidad y movida por la sabiduría" (UNESCO, 1.998; p. 23), y fundamentada en lo que Delors (1996), en el mismo orden, ha denominado los cuatro pilares que deben regir la educación de este siglo: el aprender a conocer, hacer, ser y convivir, siendo los dos últimos las bases sólidas de la responsabilidad social universitaria y del cooperativismo o solidaridad.

Se considera importante un cambio paradigmático de las teorías y prácticas de las Universidades para ayudar al desarrollo de la justicia y a la formación de ciudadanos socialmente responsables. Se requiere transitar desde una acción social centrada en la caridad y la asistencia a una basada en la justicia, los derechos y deberes ciudadanos, el reconocimiento de la necesidad y de la profunda interdependencia entre las personas de una sociedad (Castañeda, Ruiz, Viloria, Castañeda, \& Quevedo, 2007).

Las instituciones universitarias cumplen una función pública, la de educar, la cual le genera una responsabilidad social, en lo relacionado con la formación de profesionales; juega un nuevo rol social y moral más allá de asegurar la formación profesional, técnica y científica, enseñar comportamientos éticos y solidarios, en pro del desarrollo; constituye uno de los más importantes espacios para el aprendizaje y crean redes sociales basadas en la confianza, la tolerancia, el entendimiento mutuo y los valores compartidos (capital social), que ayudan al desarrollo saludable y sostenible de una sociedad y de una economía.

Los grupos de interés de una universidad incluyen, entre otros, profesores, estudiantes, cuerpo administrativo, directivos, futuros empleadores, organizaciones/instituciones, la comunidad y el sector público, los cuales se ven afectados por las decisiones que toma la 
universidad, en cuanto a la forma como preparan a sus estudiantes para que sean profesionales y ciudadanos, capaces de asumir éticamente el contexto social al que se enfrentan desde las diversas disciplinas.

Por otro lado, para Cavero (2.006), la responsabilidad social universitaria es un enfoque ético del vínculo mutuo entre universidad y sociedad. Se trata de un compromiso relevante para la solución de los problemas sociales, permite la aplicación directa del saber científico y tecnológico, así como una formación profesional más humanitaria. Mónica (2002) define la responsabilidad social universitaria como: La capacidad que tiene la universidad, de difundir y poner en práctica un conjunto de principios y valores generales y específicos, por medio de cuatro procesos básicos, considerados claves en la universidad, como son la gestión, la docencia, la investigación y la extensión universitaria (Sánchez Arza, 2011).

La responsabilidad social universitaria, ha sido asociada a proyección social/extensión, siendo que va más allá del ya conocido tercer pilar: La extensión universitaria (al lado de la formación académica y la investigación), la proyección social de la universidad. Por tanto, ha de superar la visión estrecha de la misión social Universitaria (proyección/extensión), limitada a obras filantrópicas. La totalidad de la universidad, pasa por los cuatro procesos, no solo formación e investigación, si no también, participación social y sobre todo, gestión institucional; se espera que la universidad se comprometa y permita ser traspasada horizontalmente, en palabras de Giacoman y Opazo (2002), por el concepto de sostenibilidad integral, en equilibrio dinámico con la sociedad, ha de jugar un nuevo rol social y moral en la formación profesional.

En este marco, se asocia el concepto de responsabilidad social universitaria a la capacidad de la universidad de aplicar un conjunto de principios y valores, declarados en su filosofía de gestión, en la praxis de sus funciones básicas: gestión (transparencia y calidad), docencia (enseñanza y práctica aplicada en la solución de problemas sociales), investigación y producción (de conocimientos, bienes y servicios con pertinencia social) y extensión (proyección e interacción social, proyectos de desarrollo humano y calidad de vida) con miras a responder a las demandas de su entorno; a la idea de desarrollo sustentable, sustentabilidad ciudadana y democrática, planteadas por Guédez (2003).

Responsabilidad social universitaria implica una gestión socialmente responsable de la universidad, de la organización misma (gestión institucional), en especial de los recursos humanos y ambientales, de la formación académica, de la producción del saber y los modelos epistemológicos promovidos, de la participación, del desarrollo humano sostenible de la comunidad (gestión, docencia, investigación y extensión), traducido en la suma de esfuerzos colectivos: docencia más desarrollo de capacidades, proyección social más desarrollo económico, investigación más desarrollo sostenible y gestión más desarrollo humano y desarrollo de 
capacidades, dadas las posibilidades de integración y el retorno permanente de las acciones sociales emprendidas para el mejoramiento de las funciones en coherencia con la declaración de principios de la misión, visión y práctica académica e institucional (Sánchez Arza, 2011).

\section{Reflexión personal}

En el mundo cambiante que vivimos los seres humanos, las universidades tienen que jugar y asumir un rol beligerante y esencial, impulsando el análisis de la discusión y la vía de la reflexión con trabajos, investigaciones, extensiones en su entorno, considerando temas elementales como calidad en la educación, nuevos planes de estudio adaptados a las demandas de la sociedad y de las empresas, nuevos métodos y estrategias de enseñanza-aprendizaje, articulación entre estudiantes, docentes, universidad, planes de movilidad para obtener mayores niveles de entendimiento, capacitación actualizada y compromisos o retos hacia el futuro.

La universidad del futuro tiene que jugar un rol o compromiso social con todos los actores locales, nacionales y de índole internacional para la expansión de saberes en la búsqueda de la excelencia académica, pertinencia de sus procesos, de mejoras en el capital humano puesto a disposición de la sociedad empresarial y estudiantil que cada día las haga más competitivas pero con empoderamiento de saberes y de calidad en la educación con ética empresarial y mucha responsabilidad social.

La responsabilidad social universitaria conduce hacia una universidad orientada a la solución de problemas complejos gracias a una organización académica más pluridisciplinaria que con base a especialidades separadas y fragmentadas, sino con base en el pensamiento complejo.

\section{REFERENCIAS BIBLIOGRÁFICAS}

Bank Group, W. (14 de Agosto de 2016). La responsabilidad social empresarial. https:// www.siteresources.worldbank.org.

Castañeda, M., Ruiz, M., Viloria, O., Castañeda, R., \& Quevedo, A. (8 de Noviembre de 2007). El rol de las universidades en
Delors, J. (1994). Los cuatro Pilares de la Educacion, en la Educacion encierra un tesoro. dgdaies, 91-103.

Duarte, C. (2 de Marzo de 2012). La Responsabilidad Social Empresarial. http://www.gerencia.com.

Ferrer, J. (25 de Enero de 2001). El Roll de las Universidades en el contexto Social Empresarial. Maracaibo, Venezuela: https://www.academia.edu/RevistaNEGOTIUM. 
Guedez, V. (2005). Gerencia, Cultura y Educacion. Maracaibo, Venezuela: Fondo Editorial Tropykos.

Hernandez, C. G. (12 de Febrero de 2002). Responsabilidad Social y Sistema Universitario Chileno:Vision y Espectativa de los jovenes universitarios. Universidad Catolica Chilena.

Herrera, Macias \& Sanchez. (12 de Noviembre de 2017). La Responsabilidad Social Corporativa como fuente de Satisfaccion de los empleados. http://www. archive. org/web.

Pelekais, d. C. (2010). Gestion universitaria socialmente responsable:un camino efectivo hacia el servicio comunitario. REDHECS, 25-30.

Sánchez Arza, C. J. (9 de Diciembre de 2011). El rol de las universidades en el contecto de la responsabilidad social. https://www. repositorio.ufsc.br/bitstream/handle UNESCO. (2013). Los cuatro Pilares de la Educacion, en la Educacion encierra un Tesoro. Globaleducacionmagazine, 91-103.

Vallejo, R. \&. (2011). Responsabilidad social e investigacion:retos de la universidad del siglo XXI. Redalic, 216-236. 